\title{
Applying phenomenography in guidance and counselling research
}

\author{
Jaana Kettunen \& Päivi Tynjälä
}

Jaana Kettunen ${ }^{1}$

Finnish Institute for Educational Research

P.O. Box 35

40014 University of Jyväskylä, Finland

Tel. +358408054255

Email: jaana.h.kettunen@jyu.fi

Jaana Kettunen is a researcher at the Finnish Institute for Educational Research of the University of Jyväskylä. Her research focuses on social media in career services. Recently she has also studied the ethical practice in social networking and the role of ICT in relation to national lifelong guidance policies.

\section{Päivi Tynjälä}

Finnish Institute for Educational Research

P.O. Box 35

40014 University of Jyväskylä, Finland

Tel. +358504009464

Email: paivi.tynjala@jyu.fi

Päivi Tynjälä is a Professor in research on teaching and learning in higher education at the Finnish Institute for Educational Research of the University of Jyväskylä, Finland. She has published widely both internationally and nationally and has served as the Editor-in-Chief of Educational Research Review from 2010-2013.

\footnotetext{
${ }^{1}$ Corresponding author: Jaana Kettunen Email: jaana.h.kettunen@jyu.fi
} 


\section{Applying Phenomenography in Guidance and Counselling Research}

This paper examines phenomenography as a viable qualitative approach in guidance and counselling research. A phenomenographic study maps the qualitatively different ways in which people experience a specific phenomenon and helps researchers to describe the aspects that make one way of experiencing a certain phenomenon qualitatively distinct from another. This paper presents an overview of phenomenographic research, encompassing theoretical, methodological and practical considerations. The application of this approach in guidance and counselling studies is illustrated with examples.

Keywords: phenomenography; qualitative research; methodology; method; guidance; counselling

The multifaceted, multi-layered nature of the guidance and counselling field means that it can be approached from multiple theoretical and methodological perspectives.

However, the vast majority of guidance and counselling studies are still framed within the quantitative paradigm (e.g., Sampson et al., 2014; Sted et al., 2012; Whiston, Rose, Peterson, \& Nguyen, 2013). Despite the dominance of quantitative research, qualitative research methods have begun to attract increasing attention within the field in recent decades (e.g., Berríos \& Lucca, 2006; Blustein, Kenna, Murphy, DeVoy, \& DeWine, 2005; Sted et al., 2012). This growing recognition of the value of qualitative research has enriched current understandings of career development by prompting research beyond the positivist scientific paradigms that have informed most career theories and major lines of research within the field to date (e.g., W. Patton \& McMahon, 2006; Watson, Bimrose, \& McMahon, 2015; Young \& Valach, 2000). 
Using the qualitative approach in guidance and counselling research is often advocated, based on its deeper insights into participants' views compared to quantitative methods (e.g., Ponterotto, 2002; Savickas, 2001; Willig \& Stainton-Rogers, 2008). Methodological literature suggests that qualitative research may also reveal broader perspectives on the phenomenon under investigation. The basic assumption in the qualitative approach involves multiple constructed realities (Lincoln \& Guba, 1985), meaning that people perceive reality in a variety of ways. Certain qualitative approaches, such as phenomenography, specifically search for this variation. The potential of qualitative research to contribute to social change and the development of human practice is also often highlighted. For example, Higgs and Cherry (2009) have considered the qualitative approach useful because it reveals what people think about their practice, which can then trigger them to transform practice. Thus, qualitative research may provide important tools for developing guidance and counselling practice.

Qualitative research involves a broad range of approaches or cultures of inquiry, which can be perceived as a strength. At the same time, the diversity of available approaches can make it difficult, even for experienced researchers, to select the most appropriate method for a particular study — a task made even more challenging by terms whose meanings are sometimes confusing, inconsistent and overlapping (Higgs \& Cherry, 2009). 'Whichever research approach is chosen, the discipline required of all qualitative researchers is to build and communicate transparent protocols for enacting the selected research strategy chosen as the basis for self- and external evaluation of the research strategy’ (Higgs \& Cherry, 2009, p. 8).

This paper examines phenomenography as a viable qualitative approach for use in guidance and counselling research. The main purpose is to provide a brief overview of the approach, encompassing theoretical, methodological and practical considerations, 
and to discuss the application of this approach in guidance and counselling studies. The aim is to encourage researchers within the field to consider the potential of such an approach for their future research. Based on our experiences, we believe that phenomenography provides a useful tool to capture the diversity of constructed realities in this multifaceted field of guidance and counselling and to develop practice based on research findings.

Phenomenography is distinct from the more familiar phenomenology. The father of phenomenography, Ference Marton (1988), stated that it is not an offspring of phenomenology despite their similarities. Both these schools of thought can be characterised as relational, experiential, contextual and qualitative approaches. The difference is that while phenomenology seeks to capture the essence of a phenomenon as a person experiences it, focusing on what is common to different experiences, phenomenographic studies seek to characterise the qualitative variation in the ways in which people experience a specific phenomenon (Marton, 1981; M. Q. Patton, 2002). This distinction is exemplified by the study of Larsson and Holmström (2007), who analysed the same data separately with the two approaches. The outcome of the phenomenographic analysis comprised four different ways that anaesthesiologists understood their work, while the phenomenological analysis revealed the common essence of being an anaesthesiologist. Another difference is that empirical phenomenology searches for immediate experience instead of conceptual thought, whereas phenomenography does not make this distinction as a starting point of research (Marton, 1988). The third difference is the tenet of the hierarchical nature of the description of human experience in phenomenography (Marton \& Booth, 1997), which is absent from phenomenology. For more detailed information on empirical phenomenology, see Aspers (2009). 


\section{Phenomenographic Research Approach}

Since its emergence in the late 1970s, phenomenography has become well known as a qualitative research approach for investigating at a collective level the different ways in which people experience or understand the same concept or phenomenon (e.g., Bowden \& Green, 2005; Bowden \& Marton, 1998; Bowden \& Walsh, 2000; Marton, 1981, 1986, 1994; Marton \& Booth, 1997). Over the years, phenomenographic research has been further developed into a theory of learning and awareness (Marton \& Booth, 1997). In turn, this has led to a holistic construct called the 'variation theory', which aims to describe human experience (Marton \& Tsui, 2004). As a specific qualitative approach, phenomenography has received extensive interest in research literature. Tight (2016) reports that by September 2014, over 12,000 academic publications have mentioned one or both of the terms 'phenomenography' and 'phenomenographic'.

Originating in educational research (e.g., Marton \& Säljö, 1976a, 1976b), phenomenography has since been deployed in a range of disciplines, including guidance and counselling. For example, the phenomenographic approach has been used to identify conceptions of the role of information and communication technologies related to national guidance policies (Kettunen, Vuorinen, \& Ruusuvirta, 2016), ethical practice in social networking in career services (Makela \& Kettunen, in press), leadership and management in guidance and counselling networks (Nykänen, 2011), and career practitioners' conceptions of competency in the use of social media for career services (Kettunen, Sampson, \& Vuorinen, 2015a).

Several fundamental principles underlie the phenomenographic approach.

Central to phenomenography is its non-dualist ontological perspective, in which persons and the world are considered inseparable (Bowden, 2005; Marton, 2000). A conception or a way of experiencing a specific phenomenon is perceived as a relation between the 
person and the phenomenon. People's different ways of conceptualising or experiencing the same thing are viewed as internally related, representing different meanings concerning the phenomenon in question (Åkerlind, 2003; Marton, 2000). Thus, the object of phenomenographic research is the phenomenon as experienced by individuals rather than the phenomenon itself. Phenomenography is based on a second-order perspective, focusing on how phenomena are perceived by people, rather than on a firstorder perspective, in which someone attempts to describe phenomena 'as they are' (Marton, 1981). Phenomenography also recognises that individuals may have more than one conception of a particular phenomenon (Marton \& Booth, 1997), and that their conceptions may change over time (e.g., Åkerlind, 2003; Paakkari, Tynjälä, Torppa, Villberg, \& Kannas, 2016) or even in different contexts (e.g., Täks, Tynjälä \& Kukemelk, 2016).

Phenomenography is grounded on the premise that there is a limited number of ways of experiencing a particular phenomenon and that these ways are logically related to each other. The primary outcome of a phenomenographic analysis is a structured set of logically-related categories that describe the qualitative variation in people's ways of experiencing or understanding the phenomenon in question. These categories are often described in a nested hierarchy, expanding from the least to the most complex understandings. In a phenomenographic study, besides identifying the different categories, it is also important to identify the aspects that differentiate the categories from each other, hence revealing their qualitative differences. Such categories of description should meet three quality criteria as follows: 1) Each category should describe a distinctly different way of experiencing the phenomenon. 2) Logical relationships between categories should be hierarchically represented. 3) There should 
be a limited, parsimonious number of different categories that describe variation across the sample (Marton \& Booth, 1997).

\section{Data Collection in Phenomenographic Studies}

Phenomenographic studies typically involve small groups of participants and use open, exploratory data collection to investigate the qualitatively different ways in which a certain phenomenon can be experienced or understood. Data are predominantly collected either through participant interviews or from texts written by participants in response to specific questions (e.g., Collier-Reed \& Ingerman, 2013). Other methods, such as observations, group interviews and drawings, can also be used (Marton, 1994; Marton \& Booth, 1997) but are less common.

Participant selection for phenomenographic studies involves a strategic effort to maximise diversity in the representation of participant experiences to enable an inclusive view within the aims of the study (Åkerlind, 2005a). Purposeful sampling (M. Q. Patton, 2002) is commonly used to acquire information-rich cases that offer knowledge relevant to the research objectives. This approach increases the likelihood that the variability common to a given social phenomenon will be represented in the data (Maykut \& Morehouse, 1994). For example, to properly explore the different ways in which career professionals experience social media in career services, respondents should vary in age, gender, work setting, career service experience and experience using social media in career services. Previous phenomenographic studies suggest a sample comprising 10-15 subjects as typically sufficient to capture variation and reach the saturation point at which no new information emerges from the data (Åkerlind, 2008; Trigwell, 2000). In practice, most studies employ a sample size of 20-30 participants (Bowden, 2005) although some researchers report saturation points with as few as 7 or 11 participants (Täks, Tynjälä, Toding, Kukemelk, \& Venesaar, 2014). While there is 
no recommended upper limit, the sampling must ensure that the resulting amount of data remains manageable. Töytäri and colleagues' (2016) recent study used an unusually large number of participants $(\mathrm{N}=1,622)$. The data were collected by using an open-ended question in a large online survey. The researchers report that while using such a large dataset is feasible, it does not provide additional value in terms of research results. A similar outcome would have been obtained with a much smaller number of interviews. Nonetheless, the study demonstrates that qualitative data collected from a large survey can be analysed phenomenographically.

Phenomenographic interviews are typically semi-structured, comprising a number of predetermined questions designed to direct the interviewees' focus towards the target phenomenon. Semi-structured interviews consist of open-ended questions that allow interviewees the necessary flexibility to reveal their current understandings and experiences of the phenomenon as fully and openly as possible, while providing a structure that keeps the interview on track. For example, Kettunen and colleagues (2015a, p. 46, 2015b, pp. 270-271) used the following questions when interviewing career practitioners about their conceptions of social media and competency for social media in career services: (a) 'What is the role of the career practitioner in meeting career service goals?' (b) 'What is the role of social media in career services?' (c) 'What is career service like in social media?' (d) 'What are the skills needed for social media in career services?' (e) 'How can social media be best used in career services?' In her focus group interviews on conceptions of leadership and management in guidance and counselling networks, Nykänen (2011) asked the following four questions: (a) 'What question is uppermost in your thoughts with regard to the topic of networking in guidance and counselling?' (b) 'How should multiprofessional networking collaboration be organised in order to give genuine added value to guidance 
and counselling activity?' (c) 'In your own region, what are the bottlenecks affecting guidance and counselling networking activity?' (d) 'What kind of training do you require in order to develop networking collaboration?' (p.35). Neutral follow-up questions may be used to encourage participants to elaborate on or clarify their responses, such as 'Could you explain that further?', 'What do you mean by that?' or 'Could you give me an example?' (e.g., Bowden, 2000). When asking follow-up questions, care must be taken to avoid leading the interviewees' responses. Throughout the interview, it is important that the researcher's preconceptions about the phenomenon be taken into account and (as far as possible) set aside. Phenomenographic interviews are recorded and transcribed verbatim for subsequent analysis.

\section{Phenomenographic Data Analysis}

Phenomenographic data analysis aims to uncover the different ways in which people experience or understand a certain concept or phenomenon. In general, phenomenographic analysis consists of two stages. The first involves identifying and describing participants' experiences or understandings in terms of their meaning, while the second seeks to identify the structural aspects of those meanings (e.g., Åkerlind 2005b; Marton \& Pong, 2005). Such analysis is strongly iterative, involving constant comparisons between the data and the developing categories of description, as well as between the categories themselves ( $\AA$ kerlind, 2005b). The main outcome is a structured set of categories of description, known as an outcome space. The outcome space is 'the complex of categories of description comprising distinct groupings of aspects of the phenomenon and the relationships between them' (Marton \& Booth, 1997, p. 125).

There are several ways to conduct a phenomenographic analysis, including focusing on entire transcripts (Bowden, 1995, 2000), on large chunks of each transcript (Prosser, 2000), or on quotations that have been extracted from the transcripts (Marton, 
1986, 1994). In the whole transcript approach, researchers seek the meaning of a given utterance by moving backward and forward in the transcript so as to comprehend the meaning of the utterance in context. While certain sections are inevitably perceived as more pertinent to the research question than others, utterances continue to be considered in situ (Åkerlind, 2005b); therefore, the entire transcript retains its significance throughout the analysis. In the chunking approach, related parts of the transcripts are divided into large segments and then analysed in relation to each other and to the constituted categories (Prosser, 2000). The selected quotations approach focuses on quotations or smaller parts of the text that appear similar. These are extracted from the transcripts and combined for analysis in one decontextualised 'pool of meanings', from which categories of description are derived (Marton, 1986).

The group-versus-individual approach to data analysis is another common variant in phenomenography. Typically, phenomenographic researchers work individually during data analysis, reading the transcripts and then developing a draft set of categories. The transcripts are then reread, and the categories are arranged and rearranged until they form a final set of related categories of description for a specific phenomenon. In the group process, one researcher acts exactly as an individual researcher would, while the other researchers play the devil's advocates, continuously probing the draft and seeking justifications for particular formulations in the transcripts (Bowden \& Green, 2005, 2010). Analysis followed by reanalysis continues until a collective researcher-interpreted voice is agreed on (Bowden \& Green, 2010).

Beyond these variants of data sorting methods and their emphasis on collaboration, phenomenographic data analysis practice also includes various ways of managing data and of constituting the structure. Nevertheless, significant commonalities in all phenomenographic practice clearly remain (Åkerlind, 2005b). These include 
maintaining an open mind during analyses, minimising any predetermined views or too rapid foreclosures on views about the nature of the categories of description, and keeping the focus on the transcripts and the emerging categories of description as a set.

\section{An Example of a Phenomenographic Data Analysis Process}

Although the relevant literature provides some guidelines on how to undertake a phenomenographic data analysis (e.g., Åkerlind, 2005a; Bowden \& Green, 2005; Bowden \& Walsh, 2000; Marton \& Booth, 1997), researchers must still decide about the exact manner of proceeding. Besides learning to understand and implement the standard core practices of phenomenography, researchers should make thoughtful, wellreasoned decisions regarding methodological options. This section describes two possible ways of conducting a phenomenographic analysis as a team endeavour, drawing on the authors' experiences (e.g., Kettunen et al., 2013, 2015a, 2015b, 2016; Täks et al., 2016; Töytäri, et al., 2016). Table 1 includes an example of one way of presenting research outcomes to emphasise the distinctiveness of the approach. We refer to a study that aimed to discover and describe the qualitatively different ways in which practitioners understood competency for social media in career services. The data were gathered from focus group interviews with 16 Danish and Finnish career practitioners with experience using social media in career services. (For details about the study's results, see Kettunen et al., 2015a). The general steps described here follow the guidelines and examples offered by Åkerlind (2005a, 2005b), Bowden (2000a) and Bowden and Green $(2005,2010)$.

Generally, the two approaches to conducting a phenomenographic analysis within a team are quite similar. The analysis commences after data collection and transcription are completed. All the data are combined, so the analysis can focus on similar and different meanings rather than on individuals. The transcripts are read as a 
whole for the initial identification of the main themes and their interrelations, which then allows for a more detailed analysis of the variation in meanings expressed by the participants.

Throughout the analysis, identified variation of meanings will be formed into categories of description (e.g., Marton, 1981). In line with phenomenographic principles, these categories are not predetermined but are constituted on the basis of the collected data. The first phase of the analysis focuses on identifying and describing the participants' ways of experiencing or understanding the phenomenon in general terms. Repeated readings afford greater familiarisation with the data. By focusing on the similarities and the differences in the expressed meanings, cases of variation or agreement are identified and grouped accordingly. For example, in the aforementioned study on Finnish and Danish career guidance practitioners' conceptions of competency for social media (Kettunen et al., 2015a), the first readings revealed that the practitioners described ways of using social media in career services quite differently and had varying ethical considerations.

Next in the phenomenographic research process, in order to identify key relationships that either relate the identified meanings to or distinguish them from each other, subsequent readings of participants' responses focus on similarities and differences in their expressed meanings. Gradually, by comparing and contrasting identified similarities and differences, a draft set of descriptive categories for collective meanings is developed, defined and named. Labelling meanings in the early phases of the analysis is avoided (Bowden, 2005), since it may draw the researcher's awareness towards a single direction and thereby limit further development of the emerging categories. 
The second phase of the analysis focuses on delineating the logical relationships among the various categories. Themes that run through and across the data are identified and used to structure the logical relationships both within and between the categories (Åkerlind, 2005a). The aim is to distinguish one way of seeing a phenomenon in comparison with another, more complex one (Åkerlind, 2005a; Marton \& Booth, 1997), revealing an increasing breadth of the awareness of different aspects of the phenomenon. Throughout this phase, with constant references to the data, the initial categories of description are further elaborated, fixed and defined according to the most characteristic features of each category.

A tabular approach is used to describe the structural relationships between these categories. The table is accompanied by detailed descriptions of the categories and illustrative quotations from the transcripts. The tabular format provides a direct visual outline of increasing complexity (that is, breadth of awareness) across the categories of description. This representation of the results provides a holistic view of the participants' experiences, illustrating the variation within the whole. Table 1 shows the relationships between the categories identified in the aforementioned study (Kettunen et al., 2015a). The themes running across the data are called dimensions of variation, because they reveal the aspects differentiating the categories. For example, the perceived function of social media in career services was one aspect that varied across the four identified categories (see Table 1), ranging from 'means for delivering information' (category 1), 'medium for one-to-one communication' (category 2), 'interactive working space' (category 3), to 'impetus for paradigm change and reform' (category 4).

The differences between the two approaches to conducting a phenomenographic analysis as a team endeavour pertain to how the researchers participate in ensuring a 
robust analysis of the data. In the first approach, the data are initially analysed by one researcher, while the other researchers in the team act as the devil's advocates, probing the category candidates (Bowden \& Green, 2005, 2010). The purpose of such probing is to guard against groupthink and blind spots, which can lead a researcher team to draw conclusions prematurely. In the second approach, each researcher in the team independently reads and initially analyses the data, probing the category candidates. Next, the initial results are compared, discussed and finally agreed on after some negotiations regarding interpretations. Whichever method is chosen, the group approach attempts to ensure that each category is a valid representation of the researchers' interpretations of the participants' meanings. Thus, the researchers collaboratively define the categories and their structural relationships. As emphasised by Bowden (2000), the group approach to data analysis makes it less likely that the analysis will stop partway. It helps minimise each researcher's personal perspective and remains true to the data in formulating the categories of description. Iterative rereading and redrafting continues until the saturation point (Bowden \& Green, 2010).

The final phase of the analysis focuses on ensuring that the categories of description meet the aforementioned quality criteria set out by Marton and Booth (1997). This final phase's end result is an outcome space, which describes the qualitative variation in people's ways of conceiving the phenomenon, as illustrated in a hierarchically structured table (Table 1).

Table 1. Career Practitioners' Conceptions of Competency for Social Media in Career Services: Descriptive Categories and Dimensions of Variation

File1 
Note: Reprinted from Kettunen, Sampson, and Vuorinen (2015a).

\section{Trustworthiness of Phenomenographic Research}

Qualitative research that describes the procedures employed should be clearly written to enable readers to evaluate the study's scientific rigour, hence allowing acceptance or refutation of the findings. Adopting the principles of trustworthiness is one way to ensure rigour in phenomenographic research (e.g., Collier-Reed, Ingerman, \& Berglund, 2009; Sin, 2010). According to Lincoln and Guba (1985), the trustworthiness of a qualitative study is established through the satisfactory attainment of credibility (analogous to internal validity), transferability (analogous to external validity), dependability (analogous to reliability) and confirmability (analogous to objectivity).

Credibility refers to the defensibility of the interpretations made from the data and the rigour of the process through which the findings have been obtained. Building on Booth's (1992) study, Collier-Reed and colleagues (2009) have suggested the following three measures of credibility to ensure that the outcome of phenomenographic research can be taken seriously: content-related credibility, credibility of method and communicative credibility. The first concerns the researcher's familiarity with or understanding of the topics related to the phenomenon under investigation. The second examines the extent to which the goals of the study align with its design and execution. The third involves the researcher's ability to make a persuasive argument for the interpretation of the data.

Transferability is related to the generalisability of the data, that is, the extent to which the findings may be applicable in other contexts or with other participants (Collier-Reed et al., 2009; Sin, 2010). Generally, qualitative studies' findings are unique in their respective contexts; nonetheless, transferability to other settings and groups may be possible. For example, it could be assumed that conceptions similar to those 
identified in Kettunen and colleagues' (2015a) study could be observed among other career practitioners working in similar contexts in Denmark and Finland. However, it is important to keep in mind the contextual specificity of phenomenographic studies (e.g., Marton, 1981, 1986). Even the same research subjects may express different views in different contexts. Therefore, in phenomenographic studies, it is essential to reflect on the findings' transferability by examining the situational and contextual features that might have coloured the research participants' experiences. The researcher's responsibility is to provide sufficient details to enable the reader to judge the study's transferability.

Dependability, concerns the extent to which the researcher provides readers with evidence that the research process has been logical, traceable and clearly documented. To ensure such dependability, care must be taken during the interviews, transcription and most importantly, the constitution of the categories of description (Collier-Reed et al., 2009). Some researchers suggest that working in a research group —and documenting the process - is one way to enhance the rigour of the research process (e.g., Bowden, 2005; Bowden \& Green, 2010). For example, when two interviewers (instead of one) conduct the interviews, one partner may think of asking an important follow-up question that the other may miss. Similarly, when analysing the data and forming categories, group members with more experience in qualitative analysis may notice something in the data that novice researchers may overlook.

Finally, confirmability, pertains to the extent to which findings are shown to be empirically trustworthy. To this end, the research protocol must be reported as explicitly as possible, with all phases presented accurately and clearly. Researchers must take steps to demonstrate that the findings have emerged from the data, not from their own predispositions. For instance, researchers can document the procedures for checking and 
rechecking the data throughout the study. Presenting the data with illustrative excerpts from the transcripts provides a further link between the data and the interpretations.

In addition to these strategies for enhancing the trustworthiness and quality of phenomenographic research, there are also some important general writing strategies for attaining rigour in qualitative research on guidance and counselling (e.g., Kline, 2008). According to Hays, Wood, Dahl and Kirk-Jenkins (2016), these include: (a) providing a strong rationale for the study by offering a comprehensive, balanced literature review and showing research design gaps; (b) articulating a clear statement of purpose and the relevant research question(s); (c) referring to authoritative sources when discussing methodologies; (d) providing a strong rationale for methodological decisions; (e) comparing and contrasting the findings with those of previous literature; and (f) discussing limitations and future directions for practice and research.

\section{Discussion}

This paper posits phenomenography as a viable qualitative research approach for the guidance and counselling field. Phenomenography provides a systematic way of analysing qualitative research data and makes it possible to uncover the qualitatively different ways in which various phenomena are experienced or understood. It helps researchers describe the aspects that make one way of experiencing a certain phenomenon qualitatively distinct from another, and to illustrate the underlying structure of variation across a group of participants.

Similar to any research approach, phenomenographic studies have both strengths and limitations. While from the very beginning, the findings of phenomenographic studies have received wide interest, in its early days, the research approach was criticised for lacking explicitness and specificity concerning data collection and analysis (e.g., Richardson, 1999). In other words, the methodological procedures were not 
described in enough detail for other researchers to be able to follow them in their own research. More recently, however, the methodological practices used in studies have become more transparent and guidelines for researchers have been presented (e.g., Åkerlind, 2005, Bowden \& Green, 2005).

As with other qualitative methods, questions have been raised about the validity and reliability of phenomenography. In response to these doubts, Åkerlind (2005b) has emphasised that because phenomenography makes no claims about the 'truth' of its results, external measures of validity may be irrelevant. Instead, phenomenographers refer to 'communicative validity' (accurate description of the procedures) and 'pragmatic validity' (meaningfulness of the results for the intended audience). For example, Kettunen and colleagues (2015a) presented the aforementioned study of career practitioners' conceptions of competency for social media in peer-reviewed international and national career development conferences, receiving responses that offered evidence of its communicative validity.

In his review of phenomenographic research, Tight (2016) concludes that this research design significantly enhances educational research, and its use might be extended to other fields. Phenomenography's potential contribution to guidance and counselling research and practice lies in its ability to account for differences and changes in the meanings that people express about phenomena. For example, knowledge of the variation in career practitioners' or individual citizens' guidance or counselling experiences can offer valuable information and have important impacts on practice, theory, and training in the field. To date, there are few phenomenographic studies within the field of guidance and counselling, but we encourage scholars to consider the possibilities of a phenomenographic approach in their future research. 


\section{References}

Åkerlind, G. S. (2003). Growing and developing as a university teacher: Variation in meaning. Studies in Higher Education, 28, 375-390.

doi:10.1080/0307507032000122242

Åkerlind, G. S. (2005a). Learning about phenomenography: Interviewing, data analysis and qualitative research paradigm. In J. A. Bowden \& P. Green (Eds.), Doing developmental phenomenography (pp. 63-73). Melbourne: RMIT University Press.

Åkerlind, G. S. (2005b). Variation and commonality in phenomenographic research methods. Higher Education Research \& Development, 24, 321-334. doi:10.1080/07294360500284672

Åkerlind, G. S. (2008). Growing and developing as a university teacher. Higher Education, 55, 241-254. doi:10.1007/s10734-007-9052-x

Aspers, P. (2009). Empirical phenomenology: A qualitative research approach (The Cologne Seminars). Indo-Pacific Journal of Phenomenology, 9, 1-12. doi: $10.1080 / 20797222.2009 .11433992$

Berríos, R., \& Lucca, N. (2006). Qualitative methodology in counseling research: Recent contributions and challenges for a new century. Journal of Counselling and Development, 84, 174-186.

Blustein, D. L., Kenna, A. C., Murphy, K. A., DeVoy, J. E., \& DeWine, E. B. (2005). Qualitative research in career development: Exploring the center and margins of discourse about careers and working. Journal of Career Assessment, 13, 351370. doi:10.1177/1069072705278047 
Booth, S. (1992). Learning to program: A phenomenographic perspective. Gothenburg: University of Gothenburg.

Bowden, J. (1995). Phenomenographic research: Some methodological issues. Nordisk Pedagogik, 15, 144-155.

Bowden, J. (2000). The nature of phenomenographic research. In J. Bowden \& E. Walsh (Eds.), Phenomenography (pp. 1-18). Melbourne: Royal Melbourne Institute of Technology.

Bowden, J. (2005). Reflections on the phenomenographic team research process. In J. Bowden \& E. Walsh (Eds.), Doing developmental phenomenography (pp. 1131). Melbourne: RMIT University Press.

Bowden, J., \& Green, P. (Eds.) (2005). Doing developmental phenomenography. Melbourne: RMIT University Press.

Bowden, J. A., \& Green, P. J. (2010). Relationality and the myth of objectivity in research involving human participants. In J. Higgs, N. Cherry, R. Macklin, \& R. Ajjawi (Eds.), Researching practice: A discourse on qualitative methodologies (pp. 105-121). Rotterdam, Netherlands: Sense.

Bowden, J., \& Marton, F. (1998). The university of learning. London: Kogan Page.

Bowden, J., \& Walsh, E. (Eds.) (2000). Phenomenography. Melbourne: RMIT University Press.

Booth, S. (1992). Learning to program: A phenomenographic perspective. Gothenburg, Sweden: University of Gothenburg.

Collier-Reed, B., \& Ingerman, Å. (2013). Phenomenography: From critical aspects to knowledge claim. In J. Huisman \& M. Tight (Eds.), Theory and method in higher education research (pp. 243-260). Bradford: Emerald Group Publishing Limited. 
Collier-Reed, B., Ingerman, Å., \& Berglund, A. (2009). Reflections on trustworthiness in phenomenographic research: Recognising purpose, context and change in the process of research. Education as Change, 13, 339-355.

doi:10.1080/16823200903234901

Hays, D. G., Wood, C., Dahl, H., \& Kirk-Jenkins, A. (2016). Methodological rigor in Journal of Counseling \& Development qualitative research articles: A 15-year review. Journal of Counseling \& Development, 94, 172-183.

doi:10.1002/jcad.12074

Higgs, J., \& Cherry, N. (2009). Doing qualitative research on practice. In J. Higgs, D. Horsfall, \& S. Grace (Eds.), Writing qualitative research on practice (pp. 3-12). Rotterdam: Sense Publishers.

Kettunen, J., Sampson, J.P., Jr., \& Vuorinen, R. (2015a). Career practitioners’ conceptions of competency for social media in career services. British Journal of Guidance and Counselling, 43, 43-56. doi:10.1080/03069885.2014.939945

Kettunen, J., Vuorinen, R., \& Ruusuvirta, O. (2016). European Lifelong Guidance Policy Network representatives' conceptions of the role of information and communication technologies related to national guidance policies. International Journal for Educational and Vocational Guidance, 16, 327-342. doi:10.1007/s10775-015-9313-7

Kettunen, J., Vuorinen, R., \& Sampson, J. P. (2013). Career practitioners' conceptions of social media in career services. British Journal of Guidance \& Counselling, 41, 302-317. doi:10.1080/03069885.2013.781572

Kettunen, J., Vuorinen, R., \& Sampson, J. P., Jr. (2015b). Practitioners' experiences of social media in career services. The Career Development Quarterly, 63, 268282. doi:10.1002/cdq. 12018 
Kline, W. B. (2008). Developing and submitting credible qualitative manuscripts. Counselor Education and Supervision, 47, 210-217. doi:10.1002/j.15566978.2008.tb00052.x

Larsson, J., \& Holmström, I. (2007). Phenomenographic or phenomenological analysis: Does it matter? Examples from a study on anaesthesiologists' work. International Journal of Qualitative Studies on Health and Well-being, 2, 5564. doi:10.1080/17482620601068105

Lincoln, Y. S., \& Guba, E. G. (1985). Naturalistic inquiry. Newbury Park, CA: Sage. Makela, J.P., \& Kettunen, J. (in press). Ethical practice in social networking in career services. Reflections from the field. The Career Development Quarterly.

Marton, F. (1981). Phenomenography - describing conceptions of the world around us. Instructional Science, 10, 177-200.

Marton, F. (1986). Phenomenography - a research approach investigating different understandings of reality. Journal of Thought, 21, 28-49.

Marton, F. (1988). Phenomenography: A research approach to investigating different understandings of reality. In R. R. Sherman \& R. B. Webb (Eds.), Qualitative research in education: Focus and methods (pp. 141-161). London: Falmer Press.

Marton, F. (1994). Phenomenography. In T. Husén \& T. N. Postlethwaite (Eds.), The international encyclopedia of education (2nd ed.) (pp. 4424-4429). Oxford: Pergamon Press.

Marton, F. (2000). The structure of awareness. In J. Bowden \& E. Walsh (Eds.), Phenomenography (pp. 102-116). Melbourne: RMIT University Press.

Marton, F., \& Booth, S. (1997). Learning and awareness. Mahwah, NJ: Lawrence Erlbaum Associates. 
Marton, F., \& Pong, Y. W. (2005). On the unit of description in phenomenography.

Higher Education Research \& Development, 24, 335-348.

doi:10.1080/07294360500284706

Marton, F., \& Säljö, R. (1976a). On qualitative differences in learning: I - Outcome and process. British Journal of Educational Psychology, 46, 4-11.

doi:10.1111/j.2044-8279.1976.tb02980.x

Marton, F., \& Säljö, R. (1976b). On qualitative differences in learning: II - Outcome as a function of the learner's conception of the task. British Journal of Educational Psychology, 46, 115-127. doi:10.1111/j.2044-8279.1976.tb02304.x

Marton, F., \& Tsui, A. B. M. (2004). Classroom discourse and the space of learning. Mahwah, NJ: Lawrence Erlbaum Associates.

Maykut, P., \& Morehouse, R. (1994). Beginning qualitative research: A philosophic and practical guide. London: The Falmer Press.

Nykänen, S. (2011). Towards leadership and management in guidance and counselling networks in Finland. Jyväskylä: University of Jyväskylä.

Paakkari, L., Tynjälä, P., Torppa, M., Villberg, \& Kannas, L. (2016). The development and alignment of pedagogical conceptions of health education. Teaching and Teacher Education, 49, 11-21. doi:10.1016/j.tate.2015.02.005

Patton, M. Q. (2002). Qualitative research \& evaluation methods (3rd ed.). Thousand Oaks, CA: Sage.

Patton, W., \& McMahon, M. (2006). Career development and system theory: Connecting theory and practice (2nd ed.). Rotterdam, The Netherlands: Sense.

Ponterotto, J. G. (2002). Qualitative research methods as the fifth force in psychology. The Counseling Psychologist, 30, 394-406. doi:10.1177/0011000002303002 
Prosser, M. (2000). Using phenomenographic research methodology in the context of research in teaching and learning. In J. Bowden \& E. Walsh (Eds.), Phenomenography (pp. 34-46). Melbourne, Australia: RMIT University Press.

Richardson, J. (1999). The concepts and methods of phenomenographic research. Review of Educational Research, 69, 53-82.

Sampson, J. P., Hou, P.-C., Kronholz, J. F., Dozier, V. C., McClain, M.-C., Buzzetta, M., . . Kennelly, E. L. (2014). A content analysis of career development theory, research and practice - 2013. Career Development Quarterly, 62, 290-326. doi:10.1002/j.2161-0045.2014.00085.x

Savickas, M. L. (2001). The next decade in vocational psychology: Mission and objectives. Journal of Vocational Behavior, 59, 284-290.

Sin, S. (2010). Considerations of quality in phenomenographic research. International Journal of Qualitative Methods, 9, 305-319.

Sted, G. B., Perry, J. C., Munka, L. M., Bonnett, H. R., Shiban, A. P., \& Care, E. (2012). Qualitative research in career development: Content analysis from 1990 to 2009. International Journal for Educational and Vocational Guidance, 12, 105-122. doi:10.1007/s10775-011-9196-1

Täks, M., Tynjälä, P., \& Kukemelk, H. (2016). Engineering students' conceptions of entrepreneurial learning as part of their education. European Journal of Engineering Education, 41, 53-69. doi:10.1080/03043797.2015.1012708

Täks, M., Tynjälä, P., Toding, M., Kukemelk, H., \& Venesaar, U. (2014). Engineering students' experiences of studying entrepreneurship. Journal of Engineering Education, 103(4), 573-598. doi:10.1002/jee.20056 
Tight, M. (2016). Phenomenography: The development and application of an innovative research design in higher education research. International Journal of Social Research Methodology, 19, 319-338. doi:10.1080/13645579.2015.1010284

Töytäri, A., Piirainen, A., Tynjälä, P., Vanhanen-Nuutinen, L., Mäki, K., \& Ilves, V. (2016). Higher education teachers' descriptions of their own learning: A largescale study of Finnish Universities of Applied Sciences. Higher Education Research \& Development, 6, 1284-1297. doi:10.1080/07294360.2016.1152574

Trigwell, K. (2000). A phenomenographic interview on phenomenography. In J. A. Bowden \& E. Walsh (Eds.), Phenomenography (pp. 62-82). Melbourne: RMIT University Press.

Watson, M., Bimrose, J., \& McMahon, M. (2015). Methodological considerations. In J. Bimrose, M. McMahon, \& M. Watson (Eds.), Women's career development throughout the lifespan: An international exploration (pp. 79-87). London: Routledge.

Whiston, S. C., Rose, C. S., Peterson, J. M., \& Nguyen, C. P. (2013). Content analysis of the Journal of Career Assessment. Journal of Career Assessment, 21, 367377. doi:10.1177/1069072712475160

Willig, C., \& Stainton-Rogers, W. (2008). Introduction. In C. Willig \& W. StaintonRogers (Eds.), The Sage handbook of qualitative research in psychology (pp. 112). Los Angeles, CA: Sage.

Young, R. A., \& Valach, L. (2000). Reconceptualising career theory and research: An action-theoretical perspective. In A. Collin \& R. A. Young (Eds.), The future of career (pp. 181-196). Cambridge: Cambridge University Press. 


\section{CATEGORIES}

\begin{tabular}{lllll}
\cline { 2 - 5 } $\begin{array}{l}\text { DIMENSIONS } \\
\text { OF }\end{array}$ & $\begin{array}{l}\text { Ability to use } \\
\text { social media } \\
\text { for delivering } \\
\text { information }\end{array}$ & $\begin{array}{l}\text { Ability to use } \\
\text { social media } \\
\text { for delivering } \\
\text { career } \\
\text { services }\end{array}$ & $\begin{array}{l}\text { Ability to utilise } \\
\text { social media for } \\
\text { collaborative } \\
\text { career } \\
\text { exploration }\end{array}$ & $\begin{array}{l}\text { Ability to utilise } \\
\text { social media for } \\
\text { co-careering }\end{array}$ \\
\hline $\begin{array}{l}\text { Approach to } \\
\text { social media }\end{array}$ & $\begin{array}{l}\text { technology } \\
\text { focused }\end{array}$ & $\begin{array}{l}\text { content } \\
\text { focused }\end{array}$ & $\begin{array}{l}\text { pedagogically } \\
\text { focused }\end{array}$ & $\begin{array}{l}\text { systemically } \\
\text { focused }\end{array}$ \\
$\begin{array}{l}\text { Function of } \\
\text { social media in } \\
\text { career services }\end{array}$ & $\begin{array}{l}\text { means for } \\
\text { delivering }\end{array}$ & $\begin{array}{l}\text { medium for } \\
\text { information }\end{array}$ & $\begin{array}{l}\text { interactive } \\
\text { communication }\end{array}$ & $\begin{array}{l}\text { impetus for } \\
\text { paradigm change } \\
\text { and reform }\end{array}$ \\
\hline $\begin{array}{l}\text { Online skills } \\
\text { media literacy }\end{array}$ & online writing & online discourse & online presence \\
$\begin{array}{l}\text { Ethical } \\
\text { principles }\end{array}$ & $\begin{array}{l}\text { accuracy, } \\
\text { validity }\end{array}$ & privacy & confidentiality & $\begin{array}{l}\text { professional } \\
\text { proficiency }\end{array}$ \\
$\begin{array}{l}\text { Personal } \\
\text { characteristics }\end{array}$ & motivated & patient & confident & innovative \\
\hline
\end{tabular}

